\title{
RETROSPECTIVE STUDY OF ENDOSCOPIC MANAGEMENT OF CSF RHINORRHOEA- A CASE SERIES
}

\author{
Ganesh Vihapure1, Ketan Agarwal2, Vivek Dokania ${ }^{3}$
}

${ }^{1}$ Assistant Professor, Department of Otorhinolaryngology, Krishna Institute of Medical Sciences, Deemed University, Karad. ${ }^{2}$ Resident, Department of Otorhinolaryngology, Krishna Institute of Medical Sciences, Deemed University, Karad. ${ }^{3}$ Resident, Department of Otorhinolaryngology, Krishna Institute of Medical Sciences, Deemed University, Karad.

\section{ABSTRACT}

\section{BACKGROUND}

Cerebrospinal fluid rhinorrhoea can arise as a complication of trauma, hydrocephalus, endoscopic sinus surgery or it may occur spontaneously without any identifiable cause. Surgical repair is recommended in patients who do not respond to the conservative management. In recent years Endonasal endoscopic approach has become the preferred method for repairing the CSF leaks, as it is extracranial extradural method and better outcomes have been reported as compared to the intracranial approaches.

Aim and Objective- To evaluate the results of Endonasal Endoscopic repair of CSF Rhinorrhoea.

\section{MATERIALS AND METHODS}

This retrospective study was conducted in the Department of Otorhinolaryngology, Krishna Institute of Medical Sciences, Karad, from May 2014 to November 2016. Ten patients with CSF rhinorrhoea were included in study and they were managed endoscopically. Patients were followed up for a mean duration of 12 months and the outcome was analysed.

\section{RESULTS}

The patients included in the study ranged in the age group of 20 - 47 years. Among the patients, $2(20 \%)$ were female and 8 (80\%) were males. The cause of CSF rhinorrhoea was traumatic in 7 (70\%), non-traumatic in $3(30 \%)$. In 7 (70\%) patients the site of leak was from ethmoids, in 2 (20\%) from frontal and in 1 (10\%) from sphenoid. One patient developed meningitis after surgery.

\section{CONCLUSION}

Endonasal endoscopic repair of CSF rhinorrhoea is safe, less traumatic and highly successful procedure.

\section{KEYWORDS}

Endonasal Endoscopic Repair, CSF Rhinorrhoea, CSF Leak.

HOW TO CITE THIS ARTICLE: Vi hapure G, Agarwal K, Dokania V. Retrospective study of endoscopic management of CSF rhinorrhoe a case series. J. Evolution Med. Dent. Sci. 2017;6(30):2473-2477, DOI: 10.14260/Jemds/2017/534

\section{BACKGROUND \\ MATERIALS AND METHODS}

CSF rhinorrhoea is CSF leak into the nose. It is due to communication with subarachnoid space (Meningeal fistula), i.e. opening in the arachnoid, dura and bone to permit leak of CSF through the nose. CSF leaks are associated with (10\%) risk of developing meningitis.(1) Patients with CSF rhinorrhoea present with clear watery nasal discharge, headache, recurrent meningitis, anosmia and/or unilateral intranasal masses. Diagnosing CSF rhinorrhoea includes confirming the leaking fluid as CSF, cause of CSF rhinorrhoea and localisation of the site of leak. Management of CSF rhinorrhoea includes conservative and surgical management. Conservative management is directed to reduce high intracranial pressure. The goal of surgical therapy is repair of the dural defect contributing to the CSF leak.(2) Most of CSF leaks close spontaneously within 7 to 10 days. $(3,4,5)$

Financial or Other, Competing Interest: None.

Submission 06-03-2017, Peer Review 30-03-2017,

Acceptance 05-04-2017, Published 13-04-2017.

Corresponding Author:

Dr. Ketan Agarwal,

IHR Hostel, KIMSDU,

Malkapur, Karad,

Satara-415110

Maharashtra.

E-mail: ketanagarwal@yahoo.com

DOI: $10.14260 /$ jemds $/ 2017 / 534$

Differential diagnosis includes atrophic rhinitis, allergic rhinitis, autonomic dysfunction, sinonasal polyps and temporal bone fracture.

This retrospective study was conducted in Department of Otorhinolaryngology, Krishna Institute of Medical Sciences, Karad.

\section{Inclusion Criteria}

1. Patients with CSF Rhinorrhoea having anterior skull base defect.

2. Patients with CSF Rhinorrhoea not responding to conservative management.

\section{Exclusion Criteria}

1. Unconscious patients.

2. Skull base defect more than $15 \mathrm{~mm}$.

10 patients with CSF Rhinorrhoea who underwent Endonasal endoscopic repair from May 2014 to November 2016 were analysed. Detailed history was taken including onset, duration, severity, laterality, history of facial trauma, history of sinus surgery or neurosurgical procedures, history of recurrent meningitis. Diagnostic nasal endoscopy was done in all patients. CSF was confirmed by beta- 2 transferrin. HRCT paranasal sinus was done in all cases with MRI and CT cisternography done in selected cases. Prophylactic broad 
spectrum antibiotics and acetazolamide were administered to all of the patients.

Endonasal endoscopic repair was done using 0 and 70 degree rigid endoscope under General anaesthesia. Defect was localised and confirmed by doing Valsalva manoeuvre by anaesthetist. On Valsalva manoeuvre pulsation of dura and pulsating discharge of CSF through fistula was visualised. The graft bed was prepared by removing a cuff of normal mucosa and fibrous tissue off the bone for $3-4 \mathrm{~mm}$ surrounding the defect. Defect was first occluded with fat harvested from thigh; fat was placed in hourglass manner and then fascia lata was placed over it. Fibrin glue was applied and Gelfoam was kept over it. Light nasal packing was done.

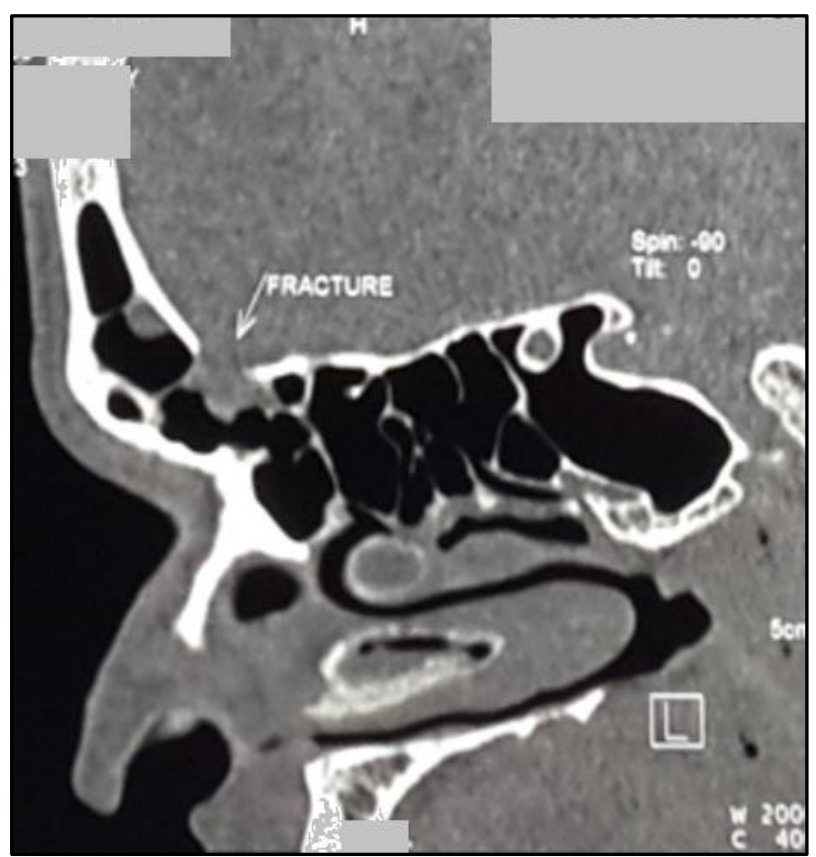

Table/Figure 1. CT Scan Image showing Posterior Table of Frontal Bone Fracture

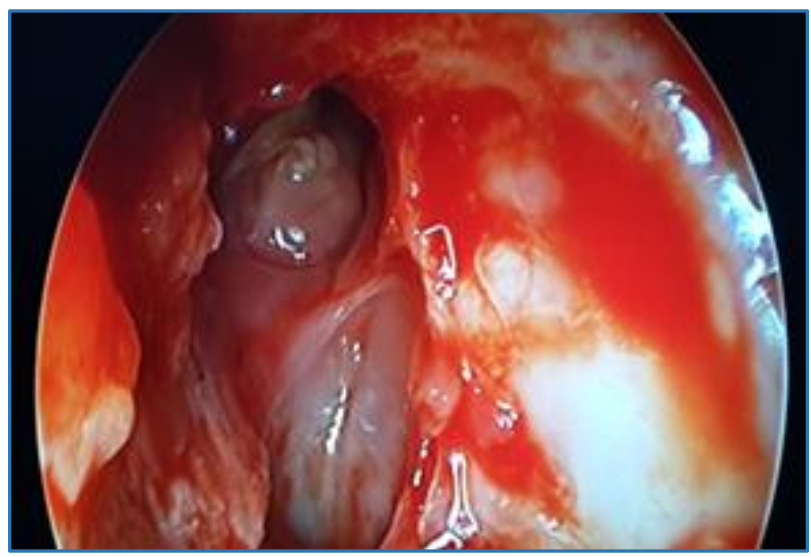

Table/Figure 2. Endoscopic Picture showing Bony Defect

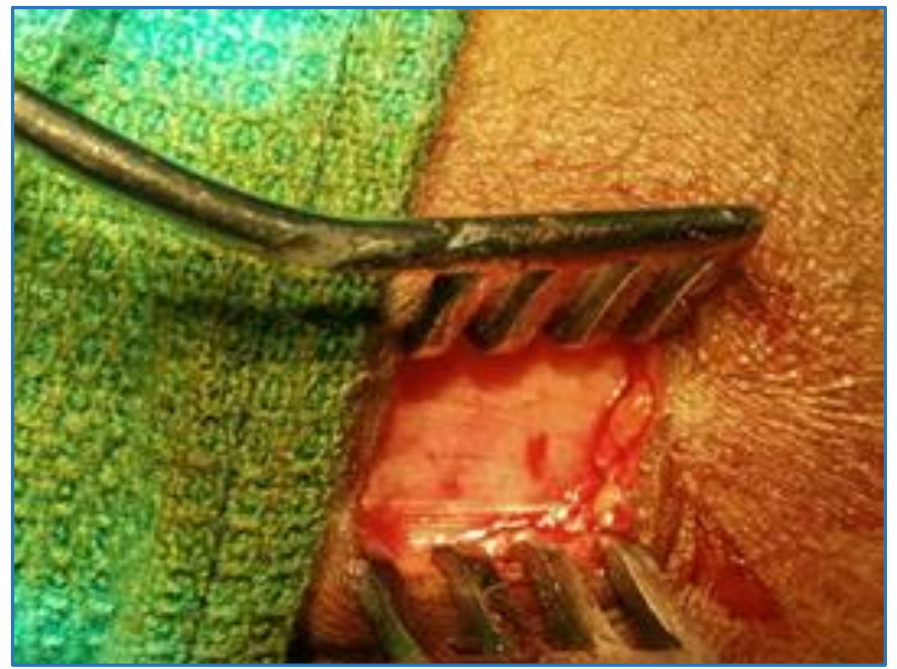

Table/Figure 3. Harvesting of Fascia Lata Graft

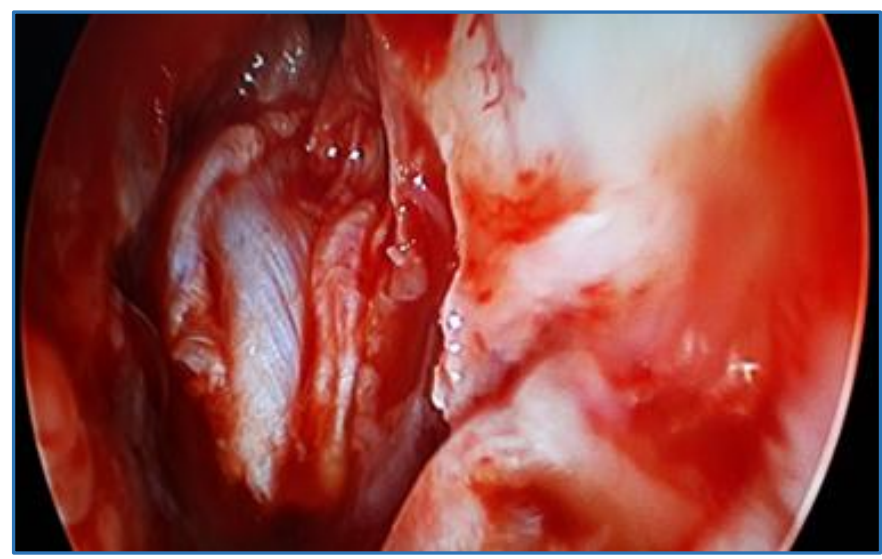

Table/Figure 4. Placement of Fascia Lata Graft

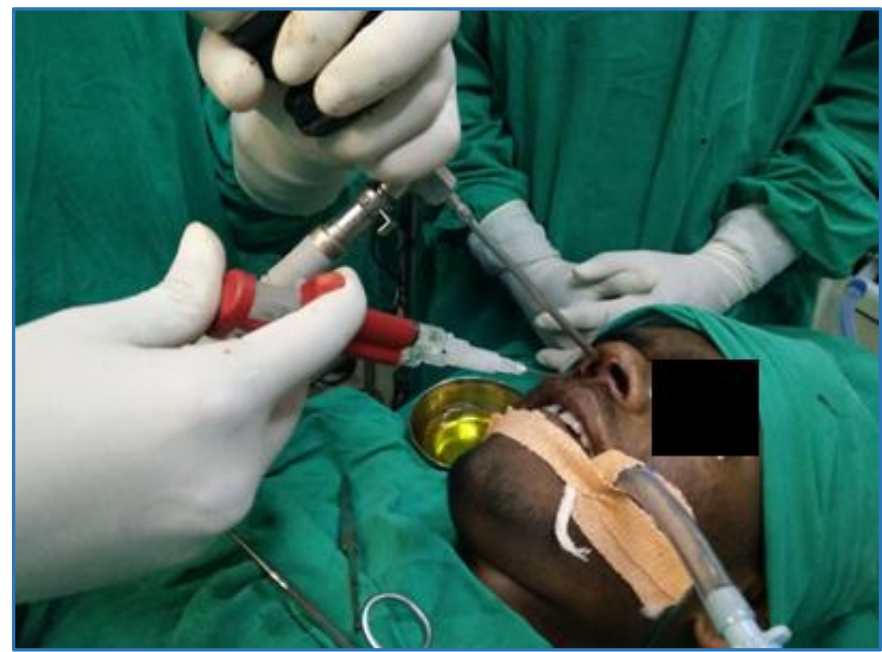

Table/Figure 5. Application of Fibrin Glue 
Postoperatively, all patients were advised strict bed rest with Propped up position. Parenteral IV antibiotic were given along with laxative, cough suppressant, acetazolamide and kesol. Patient was advised to avoid straining and lifting heavy weights. Nasal pack was removed on postop day 5. Patients were followed up regularly for a period of 1 year.

\section{RESULTS}

Among the 10 patients who were included in the study, there were 8 males and 2 females. Age group varied from 20 to 47 years.

\begin{tabular}{|c|c|c|}
\hline Age Group & Number of Males & Number of Females \\
\hline $20-25$ & 2 & 0 \\
\hline $26-30$ & 3 & 1 \\
\hline $31-35$ & 2 & 0 \\
\hline $36-40$ & 0 & 1 \\
\hline $41-45$ & 0 & 0 \\
\hline $46-50$ & 1 & \\
\hline \multicolumn{2}{|c|}{ Table/Figure 6. Age Distribution } \\
\hline
\end{tabular}

The most frequent site of cranionasal fistula was roof of ethmoids $(7,70 \%)$ followed by 2 in frontal sinus $(20 \%)$ and 1 in sphenoid sinus $(10 \%)$. None of the patients had bilateral leaks or prior attempted repair.

\begin{tabular}{|c|c|c|c|}
\hline \multirow{2}{*}{ Age Group } & \multicolumn{3}{|c|}{ Site of CSF Leak } \\
\cline { 2 - 4 } & Ethmoids & Frontal & Sphenoid \\
\hline $20-25$ & 2 & - & - \\
\hline $26-30$ & 2 & 1 & 1 \\
\hline $31-35$ & 1 & - & - \\
\hline $36-40$ & - & - & - \\
\hline $41-45$ & 1 & - & - \\
\hline $46-50$ & 1 & \\
\hline
\end{tabular}

Out of 10, 7 patients had traumatic cause for CSF rhinorrhoea amongst which 6 were due to head trauma and 1 due to iatrogenic trauma secondary to FESS; 3 patients had non-traumatic cause of CSF leak, amongst which 2 were spontaneous and 1 was secondary to pituitary tumour

\begin{tabular}{|c|c|c|}
\hline \multirow{2}{*}{ Age Group } & Traumatic & Cause of CSF Rhinorrhoea \\
\cline { 2 - 3 } & 1 & - \\
\hline $20-25$ & 3 & 2 \\
\hline $26-30$ & 1 & - \\
\hline $31-35$ & - & - \\
\hline $36-40$ & 1 & - \\
\hline $41-45$ & 1 & \\
\hline $46-50$ & \multicolumn{3}{|c|}{ Table/Figure 8. Cause of CSF Leak } \\
\hline \multicolumn{3}{|c}{} \\
\hline
\end{tabular}

None of the patients had any intra-operative complications. One patient developed post-operative meningitis.

\section{DISCUSSION}

In our study, a diverse age group of patients from 20 to 47 years underwent endoscopic repair of CSF leaks. Males were predominantly affected with a male-to-female ratio of $4: 1$, in concordance with other studies. $6,7,8)$

Ommaya et al $(9,10,11)$ gave aetiological classification of CSF rhinorrhoea. The most common site of leak post trauma are the lateral lamella of the cribriform plate and the posterior ethmoids near the anteromedial wall of the sphenoid as ethmoid roof are the thinnest, dura is tightly adherent to bone in this area, natural dehiscence created by Anterior Ethmoidal Artery and prolongation of the subarachnoid space along the olfactory nerve rootlets.

Head trauma and iatrogenic trauma are the two most common causes of CSF rhinorrhoea, while congenital, spontaneous and tumour invasion are relatively rare. This is in concordance with other studies. $(6,12,8)$

Cribriform plate was the predominant site of leak in our study, as found in literature.(12,13)

Beta-2 transferrin assay is more specific for CSF, but in case of associated orbital injuries this can be unreliable due to the presence of beta- 2 transferrin in vitreous humour.(14) It has sensitivity of near $100 \%$ and a specificity of about $95 \% .{ }^{(15)}$ 
Stone et al(2) suggest that high-resolution CT is a useful screening examination for the initial workup of CSF rhinorrhoea. CT cisternography uses metrizamide and is useful in pinpointing leak location. MR cisternography is helpful for detecting inactive fistulas.

None of the patients had history of recurrent meningitis nor had history of bilateral leaks or prior attempted repair.

All patients underwent endoscopic repair of CSF leak with a $90 \%$ success rate at first attempt. This was in concordance with the results obtained in other studies.(16)

The high success rate was attributed to the multi-layered repair using fascia lata, adipose tissue. Various other graft materials have been used in other studies to repair the defectnasal cartilage and mucoperichondrium, middle turbinate flap and fibrin glue. $(6,17,18)$ We used fibrin glue in all the cases.

Several authors recommend the use of postoperative lumbar drain. However, in our study, we did not find it necessary and lumbar drain was not used in any of the patients.

The patients were followed up for 6 to 12 months. One patient developed postoperative meningitis.

Endonasal endoscopic repair of cerebrospinal fluid leaks is a major challenge for otorhinolaryngologists and skull base surgeons. The advances in technology have permitted its repair by the minimally invasive endoscopic technique. It is currently accepted that endoscopic intranasal management of CSF rhinorrhoea is the preferred method of surgical repair with higher success rates and less morbidity than intracranial surgical repair in selected cases.(19) This approach is costeffective, less time consuming, has minimal morbidity and mortality, and a very high success rate as compared to the open intracranial approach. Dural defects though rare, must be closed regardless of the cause due to potential risk of lifethreatening complications like meningitis and pneumocephalus.

The value of antibiotic prophylaxis in patients with CSF leakage is debatable. In a literature review, Brodie(20) concluded that individually each of the studies evaluated demonstrated no significant difference in the incidence of meningitis with prophylactic antibiotic therapy.

\section{CONCLUSION}

Endoscopic repair of CSF rhinorrhoea provides a better field of vision with enhanced illumination, magnified angle of visualisation and accurate positioning of the graft under direct visualisation. The high success rate attached with this should make it the preferred approach in traumatic and nontraumatic CSF leaks, not associated with intracranial space occupying.

\section{REFERENCES}

[1] Jones NS, Becker DG. Advances in the management of CSF leaks. BMJ 2001;322:122-3.

[2] Stone JA, Castillo M, Neelon B, et al. Evaluation of CSF leaks: high-resolution CT compared with contrastenhanced CT and radionuclide cisternography. AJNR Am J Neuroradiol 1999;20(4):706-12.
[3] Chan DT, Poon WS, IP CP, et al. How useful is glucose detection in diagnosing cerebrospinal fluid leak? The rational use of CT and beta- 2 transferrin assay in detection of cerebrospinal fluid fistula. Asian J Surg 2004;27(1):39-42.

[4] Yilmazlar S, Arslan E, Kocaeli H, et al. Cerebrospinal fluid leakage complicating skull base fractures: analysis of 81 cases. Neurosurg Rev 2006;29(1):64-71.

[5] Brodie HA, Thompson TC. Management of complications from 820 temporal bone fractures. Am J Otol 1997;18(2):188-97.

[6] Zweig JL, Carrau RL, Celin SE, et al. Endoscopic repair of cerebrospinal fluid leaks to the sinonasal tract: predictors of success. Otolaryngol Head Neck Surg 2000;123(3):195-201.

[7] Mirza S, Thaper A, McClelland L, et al. Sinonasal cerebrospinal fluid leaks: management of 97 patients over 10 years. Laryngoscope 2005;115(10):1774-7.

[8] Cassano M, Felippu A. Endoscopic treatment of cerebrospinal fluid leaks with the use of lower turbinate grafts: a retrospective review of 125 cases. Rhinology 2009;47(4):362-8.

[9] Obrador S. Primary non-traumatic spontaneous cerebro-spinal fluid rhinorrhoea with normal cerebrospinal fluid pressure. Arch Neurol Neurochir Psychiatr 1972;111(2):369-76.

[10] Ommaya AK, Chiro DI. Hydrocephalus and leaks. In: Wager H (edr). Principles of nuclear medicine. $2^{\text {nd }}$ edn. Philadelphia: Saunder 1995.

[11] Spetzler RF, Wilson CB. Dural fistula and their repair. In: Youman JR (edr). Neurological surgery. $2^{\text {nd }}$ edn. Philadelphia: Saunder 1982:2209-27.

[12] Lindstrom DR, Toohill RJ, Loehrl TA, et al. Management of cerebrospinal fluid rhinorrhea: the medical college of Wisconsin experience. Laryngoscope 2004;114(6): 969-74.

[13] Lanza DC, O’Brien DA, Kennedy DW. Endoscopic repair of cerebrospinal fluid fistulae and encephaloceles. Laryngoscope 1996;106(9 Pt 1):1119-25.

[14] Ryall RG, Peacock MK, Simpson DA. Usefulness of beta 2-transferrin assay in the detection of cerebrospinal fluid leaks following head injury. J Neurosurg 1992;77(5):737-9.

[15] Skedros DG, Cass SP, Hirsch BE, et al. Sources of error in use of beta- 2 transferrin analysis for diagnosing perilymphatic and cerebral spinal fluid leaks. Otolaryngol Head Neck Surg 1993;109(5):861-4.

[16] Hughes RG, Jones NS, Robertson IJ. The endoscopic treatment of cerebrospinal fluid rhinorrhoea: the Nottingham experience. J Laryngol Otol 1997;111(2): 125-8.

[17] Burns JA, Dodson EE, Gross CW. Transnasal endoscopic repair of cranionasal fistulae: a refined technique with long-term follow-up. Laryngoscope 1996;106(9): 1080-3.

[18] Lee DH, Lim SC, Joo YE. Treatment outcomes of endoscopic repairs of sinonasal cerebrospinal fluid leaks. J Craniofac Surg 2011;22(4):1266-70. 
[19] Jones ME, Reino T, Gnoy A, et al. Identification of intranasal cerebrospinal fluid leaks by topical application with fluorescein dye. Am J Rhinol 2000;14(2):93-6.
[20] Brodie HA. Prophylactic antibiotics for posttraumatic cerebrospinal fluid fistulae. A meta-analysis. Arch Otolaryngol Head Neck Surg 1997;123(7):749-52. 